\title{
Learning Very Simple Matrix Grammar
}

\author{
M. Iffath Mubeen \\ Department of Mathematics \\ Government Arts College for \\ Men (Auto) \\ Chennai-35, Tamil Nadu, India
}

\author{
J. D. Emerald Princess \\ Sheela \\ Department of Mathematics \\ Queen Mary's College (Auto) \\ Chennai-4, Tamil Nadu, India
}

\author{
D. G. Thomas \\ Department of Mathematics \\ Madras Christian College \\ (Auto) \\ Chennai-59, Tamil Nadu, India
}

\begin{abstract}
A linguistic model to generate matrices (arrays of terminals) to recognize pictures was introduced by Rani Siromoney [1]. Yokomori introduced very simple grammars and studied the problem of identifying the class in the limit from positive data [2]. Here a new grammar called very simple matrix grammar is introduced and shown that this class is polynomial time identifiable in the limit from positive data.
\end{abstract}

\section{General Terms}

Matrix grammar and languages, context-free grammar, Greibach Normal Form, simple deterministic.

\section{Keywords}

Very simple matrix grammar and language, a-handle rule, positive presentation, inference from positive data, characteristic sample, schema representation.

\section{INTRODUCTION}

The study of syntactic methods of describing pictures considered as connected, digitized finite arrays in a two dimensional plane have been of great interest. Picture languages generated by array grammars or recognized by array automata have been advocated since the 1970s for problems arising in the frame work of pattern recognition and image processing.

A digitized picture is a finite rectangular array of points or elements each of which is associated with it one of a discrete finite set of values. Thus a picture can be represented as a $m \times n$ matrix in which each entry $a_{i j} 1 \leq i \leq m, 1 \leq j \leq n$ has one of the values, say $\mathrm{v}_{1}, \mathrm{v}_{2}, \ldots \mathrm{v}_{\mathrm{k}}[3]$.

A linguistic model for the generation of matrices (rectangular arrays of terminals) by the substitution of regular sets into well known families of formal languages has been proposed in [4]. Some interesting classes of pictures including certain letters of the alphabet, kolam, (traditional picture patterns used to decorate the floor in south Indian homes) and wall paper designs (repetitive patterns) can be generated by certain grammars

In this paper, we define very simple matrix languages and study how they are consistent with positive data by identifying a ground interpretation for them and show how they are polynomial time identifiable in the limit just as the class of very simple grammars which includes only context free languages. Simple deterministic languages have been defined with respect to Automata for regular languages and learning has been done [5]. Here we are considering contextfree matrix grammar and languages. And we introduce a very simple matrix grammar and language; study its properties and learning.

\section{BASIC DEFINITIONS}

Let $\sum$ be a finite alphabet and $\sum^{*}$ be the set of all finite length strings over $\sum$. Further, let $\sum^{+}=\sum^{*}-\{\lambda\}$, where $\lambda$ is the null string. By len $(u)$ we denote the length of the string u. A language over $\sum$ is a subset of $\sum^{*}$. For a string $\mathrm{w}$ in $\sum^{*}$, alph (w) denotes the set of terminal symbols appearing in w. For a language $\mathrm{L}, \operatorname{alph}(\mathrm{L})=\bigcup_{w \in L} \operatorname{alph}(\mathrm{w})$.

Definition 2.1 Let $\sum$ be an alphabet set-a finite non empty set of symbols. A matrix (or an image) over $\sum$ is an $m x n$ rectangular array of symbols from $\sum$ where $m, n \geq 0$. The set of all matrices over $\sum$ (including $\Lambda$ ) is denoted by $\sum^{* * *}$ and $\Sigma^{++}=\sum^{* *}-\{\Lambda\}$, where $\Lambda$ is the empty image.

Definition 2.2 R (M) and C (M) respectively denote the number of rows and columns of a given matrix $\mathrm{M}$.

Definition 2.3 Let $\sum^{*}$ denote the set of horizontal sequences of letters from $\sum$ and $\Sigma^{+}=\sum^{*}-\{\varepsilon\}$, where $\varepsilon$ is the identity element (of length zero). $\sum *$ denotes the set of all vertical sequences of letters over $\sum$, and $\sum_{+}=\sum *-\{\varepsilon\}$. Length of the given string $\mathrm{s}$ is denoted by $|\mathrm{s}|$. Precisely, if $\mathrm{s} \in \Sigma^{+}$then $|s|=C(s)$ and if $s \in \sum_{+}$then $|s|=R(s)$.

Definition 2.4 We use the operators $\Theta$ for row concatenation and $\phi$ for column concatenation for arrays. If

$$
\begin{aligned}
& a_{11} \ldots a_{1 n} \quad b_{11} \ldots b_{1 n} \text {, }
\end{aligned}
$$

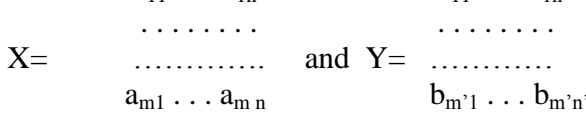

$\mathrm{X} \Theta \mathrm{Y}$ is defined only when at least one of them is $\Lambda$ or $n=n$ ' and is given by

$$
\begin{aligned}
& a_{11} \ldots a_{1 n} \\
& \mathrm{X} \Theta \mathrm{Y}= \\
& \text {........ } \\
& a_{m 1} \ldots a_{m n} \\
& b_{11} \ldots b_{1 n} \text {, } \\
& \text {........ } \\
& \text {............. } \\
& b_{m^{\prime} 1} \ldots b_{m}{ }^{\prime n}
\end{aligned}
$$

$\mathrm{X} \phi \mathrm{Y}$ is defined only when at least one of them is $\Lambda$ or $\mathrm{m}=\mathrm{m}$ ' and is given by

$$
\mathrm{X} \phi \mathrm{Y}=\begin{array}{ll}
\mathrm{a}_{11} \ldots \mathrm{a}_{1 \mathrm{n}} & \mathrm{b}_{11} \ldots \mathrm{b}_{1 \mathrm{n}}, \\
\ldots \ldots \ldots & \ldots \ldots \ldots \ldots \\
\ldots \ldots \ldots \ldots & \ldots \ldots \ldots \ldots \\
\mathrm{a}_{\mathrm{m} 1} \ldots \ldots \mathrm{a}_{\mathrm{m} n} & \mathrm{~b}_{\mathrm{m}}{ }^{\prime} 1 \ldots \mathrm{b}_{\mathrm{mn}}
\end{array}
$$

Definition 2.5 Let $\mathrm{x}$ be a matrix (or an image) defined over $\sum$ then $(x)^{i+1}=(x)^{i} \phi x$ and $(x)_{i+1}=(x)_{i} \Theta x, i \geq 1$.

Definition 2.6 Let us define a mapping $\chi$ as follows: $\Sigma^{+} \rightarrow \sum_{+}$ 
For any string $s=a_{1} a_{2} \ldots a_{n} \in \sum^{+}$

$$
\chi(\mathrm{s})=\quad \cdot \begin{aligned}
& \mathrm{a}_{1} \\
& \mathrm{a}_{2} \\
& \cdot \\
& \cdot \\
& \mathrm{a}_{\mathrm{n}}
\end{aligned}
$$

i.e. $\chi(s)=a_{1} \Theta a_{2} \Theta \ldots . \Theta a_{n}$

Definition 2.7 A matrix (or an image) is defined as follows:

Let $c_{1}, c_{2}, \ldots, c_{n} \in \Sigma^{+}$be strings of same length.

We write $\mathrm{I}=\mathrm{c}_{1} \Theta \mathrm{c}_{2} \Theta \ldots . \Theta \mathrm{c}_{\mathrm{n}}$ is the matrix (or an image) represented by the image

$$
\chi\left(\mathrm{c}_{1}\right) \Phi \chi\left(\mathrm{c}_{2}\right) \Phi \chi\left(\mathrm{c}_{3}\right) \ldots \Phi \chi\left(\mathrm{c}_{\mathrm{n}}\right)
$$

\section{Example 2.1}

If $\mathrm{c}_{1}=\mathrm{abc}, \mathrm{c}_{2}=\mathrm{efg}, \mathrm{c}_{3}=\mathrm{ijk}$ then

$\mathrm{I}=\mathrm{c}_{1} \Theta \mathrm{c}_{2} \Theta \mathrm{c}_{3}=\chi\left(\mathrm{c}_{1}\right) \Phi \chi\left(\mathrm{c}_{2}\right) \Phi \chi\left(\mathrm{c}_{3}\right)$ is the image

$\begin{array}{lll}\mathrm{a} & \mathrm{e} & \mathrm{i} \\ \mathrm{b} & \mathrm{f} & \mathrm{j} \\ \mathrm{c} & \mathrm{g} & \mathrm{k}\end{array}$

We now recall the notions of matrix grammar [1] and very simple grammar [2]

Definition 2.8 Let $G=\left(V_{N}, \sum, P, S\right)$ be a context-free grammar (CFG) in Greibach Normal Form (GNF), i.e., each rule of $P$ is of the form $A \rightarrow a \alpha$, where $A \in V_{N}, a \in \sum$, $\alpha \in \mathrm{V}_{\mathrm{N}}{ }^{*}$.

For each terminal symbol a $\in \sum$, a rule whose right hand side is of the form a $\alpha$, (where $\alpha \in \mathrm{V}_{\mathrm{N}}{ }^{*}$ ) is called an a-handle rule.

Then G is said to be Very Simple iff for each a in $\sum$, there exists exactly one a-handle rule in P.

A language L is said to be Very Simple iff there exists a Very Simple CFG G such that $\mathrm{L}=\mathrm{L}(\mathrm{G})$ holds. (Note that since every simple grammar is $\lambda$ - free, so is every simple language).

Example 2.2 Let $\Sigma=\{a, b, c, d\}$. Consider a CFG $\mathrm{G}=(\{\mathrm{S}, \mathrm{A}, \mathrm{B}\}, \Sigma, \mathrm{P}, \mathrm{S})$, where $\mathrm{P}$ consists of the following: $\mathrm{S} \rightarrow \mathrm{aAB}, \mathrm{A} \rightarrow \mathrm{aA}, \mathrm{B} \rightarrow \mathrm{bB}, \mathrm{A} \rightarrow \mathrm{c}, \mathrm{B} \rightarrow \mathrm{d}$. The grammar $\mathrm{G}$ is Very Simple and $\mathrm{L}(\mathrm{G})=\left\{\mathrm{a}^{\mathrm{m}} \mathrm{c} \mathrm{b}^{\mathrm{n}} \mathrm{d} / \mathrm{m}, \mathrm{n} \geq 0\right\}$.

Definition 2.9 (Matrix Grammars) A Phrase Structure Matrix Grammar(PSMG), Context Sensitive Matrix Grammar(CSMG), Context Free Matrix Grammar(CFMG), Right Linear Matrix Grammar(RLMG) is a two tuple $G=\left(G, G^{\prime}\right)$, where $G=(V, I, P, S)$ is a Phrase Structure Grammar(PSG), Context Sensitive Grammar(CSG), Context Free Grammar(CFG), Right Linear Grammar(RLS), with $\mathrm{V}=$ finite set of horizontal non-terminals , $\mathrm{I}=$ a finite set of intermediates $=\left(S_{1}, S_{2}, \ldots S_{k}\right), P=$ a finite set of PSG(CSG, $C F G$, RLG) production rules called horizontal production rules and

$\mathrm{S}$ is the start symbol. $\mathrm{S} \in \mathrm{V}$, and $\mathrm{V} \cap \mathrm{I}=\phi$.

$\mathrm{G}_{\mathrm{i}}{ }^{\prime}=\bigcup_{i=1}^{k} G_{i}^{\prime}$ where $\mathrm{G}_{\mathrm{i}}{ }^{\prime}=\left(\mathrm{V}_{\mathrm{i}}, \mathrm{T}_{\mathrm{i}}, \mathrm{P}_{\mathrm{i}}, \mathrm{S}_{\mathrm{i}}\right), \mathrm{i}=1,2 \ldots \mathrm{k}$ are Right

Linear Grammars with $\mathrm{T}_{\mathrm{i}}=$ a finite set of terminals, $\mathrm{V}_{\mathrm{i}}=$ finite set of vertical non-terminals, $S_{i}$ the start symbol and $P_{i}$ finite set of right linear production rules, $V_{i} \cap V_{j}=\phi$ if $i \neq j$.

Derivations are defined as follows: First a string $S_{1} S_{2} \ldots S_{n} \in I$ is generated horizontally using the horizontal production rules
$P$ in $G$ i.e. $S \Rightarrow S_{1} S_{2} \ldots S_{n} \in I$ and then vertical derivations proceed using the rules $P_{i}$ of $G_{i}^{\prime}$ in $G^{\prime}$

Definition 2.10 (Matrix Language) The set of all matrices generated by $\mathrm{M}$ is defined to be $\mathrm{L}(\mathrm{M})=\left\{m \times n\right.$ arrays $\left[a_{\mathrm{ij}}\right]$,

$\left.\mathrm{i}=1 \ldots, m, \mathrm{j}=1 \ldots, n, m, n \geq 1 / \mathrm{S}_{1} \ldots \mathrm{S}_{\mathrm{n}} \Downarrow^{*}\left[a_{\mathrm{ij}}\right]\right\}$

$\mathrm{L}(\mathrm{M})$ is called a Phrase-Structure Matrix Language (PSML) (Context-Sensitive Matrix Language (CSML), Context-Free Matrix Language (CFML), Regular Matrix Language (RML)) if $G$ is a (PSMG, CSMG, CFMG, RLMG).

Derivation trees for CFML and RML can be defined similar to derivation trees for a context -free language. Chomskian hierarchy can be extended to matrices and it can be established that the family of RML $\subset$ the family of CFML $\underset{\neq}{\subset}$ the family of CSML $\underset{\neq}{\subset}$ the family of PSML

\section{VERY SIMPLE CONTEXT-FREE MATRIX GRAMMAR}

Definition 3.1 A matrix grammar $M=\left(G, G^{\prime}\right)$ is said to be a context-free matrix grammar i.e. (CF: $\mathrm{CF}$ ) matrix grammar if $\mathrm{G}$ is a context-free grammar $\mathrm{G}=(\mathrm{V}, \mathrm{I}, \mathrm{P}, \mathrm{S})$ where $\mathrm{I}=\left\{\mathrm{S}_{1}, \mathrm{~S}_{2}, \ldots \mathrm{S}_{\mathrm{n}}\right\}$ and each $\mathrm{G}^{\prime}=\left(\mathrm{G}_{1}{ }^{\prime}, \mathrm{G}_{2}{ }^{\prime}, \ldots \mathrm{G}_{\mathrm{k}}{ }^{\prime}\right)$ where each $\mathrm{G}_{\mathrm{i}}{ }^{\prime}=\left\{\mathrm{V}_{\mathrm{i}}, \mathrm{Ti}, \mathrm{Pi}, \mathrm{Si}\right\}$ are length equivalent context- free grammars if there exists strings $\alpha_{1} \alpha_{2} \ldots \alpha_{k}$ such that $\alpha_{\mathrm{i}} \in \mathrm{L}\left(\mathrm{G}_{\mathrm{i}}{ }^{\prime}\right)$, then $\left|\alpha_{1}\right|=\left|\alpha_{2}\right|=\ldots=\left|\alpha_{\mathrm{k}}\right|, 1 \leq \mathrm{i} \leq \mathrm{k}$

Let $\mathrm{I}=\mathrm{c}_{1} \Theta \mathrm{c}_{2} \Theta \ldots . \Theta \mathrm{c}_{\mathrm{n}}$ be an image defined over $\Sigma . I \in M(G)$ iff there exists $S_{1}, S_{2} \ldots S_{n} \in L(G)$ such that $c_{j} \in$ $\mathrm{L}\left(\mathrm{G}_{\mathrm{j}}\right), \quad 1 \leq \mathrm{j} \leq \mathrm{n}$. The string $\mathrm{S}_{1} \mathrm{~S}_{2} \ldots \mathrm{S}_{\mathrm{n}}$ is said to be an intermediate string deriving I with respect to $\mathrm{M}$. Note that there can be more than one intermediate string deriving I. The family of languages generated by $(\mathrm{X}: \mathrm{Y}) \mathrm{MG}$ is denoted as $(\mathrm{X}: \mathrm{Y}) \mathrm{ML}$ where $\mathrm{X}, \mathrm{Y} \in\{\mathrm{CF}, \mathrm{R}\}$.

Definition 3.2 A context-free matrix grammar $M=\left(G, G^{\prime}\right)$ is said to be a very simple matrix grammar if it satisfies the following properties

i) The context free grammars $G$ and $G_{i}{ }^{\prime}$ s in $G^{\prime}$ are all in Greibach Normal Form in the strict sense, that is each rule in $\mathrm{P}$ and Pi's are of the form $\mathrm{A} \rightarrow \mathrm{a} \alpha$ where $\mathrm{A} \in \mathrm{I}$ or $\mathrm{V}_{\mathrm{i}}$, $\mathrm{a} \in \mathrm{I}$ or $\mathrm{T}_{\mathrm{i}}$ and $\alpha \in \mathrm{V}^{*}$ or $\mathrm{V}_{\mathrm{i}}{ }^{*}$ and no right hand side of the rules contains the starting non-terminal.

ii) For each intermediate symbol $S_{\mathrm{i}}$ in $\mathrm{G}$ there exists exactly one Si-handle rule in $\mathrm{G}$.

iii) For each $a_{i} \in T_{i}$ in $G_{i}{ }^{\prime}$, there exists exactly one $a_{i}$ - handle rule in $P_{i}$

iv) For each $S_{i} \rightarrow a_{i} \alpha_{i}$ or $A_{i} \rightarrow a \alpha_{i}$ in each $G_{i}{ }^{\prime}$ where $\mathrm{S}_{\mathrm{i}}, \mathrm{A}_{\mathrm{i}} \in \mathrm{V}_{\mathrm{i}}$, a $\in \mathrm{T}_{\mathrm{i}}$ and $\alpha_{\mathrm{i}} \in \mathrm{V}_{\mathrm{i}}$ *, all $\alpha_{\mathrm{i}}$ 's are of same length. That is if $A_{1} \rightarrow a_{1} \alpha_{1}, \alpha_{1}$ in $G_{1}^{\prime}, A_{2} \rightarrow a_{2} \alpha_{2}, \alpha_{2}$ in $G_{2}^{\prime}$, and $\mathrm{A}_{3} \rightarrow \mathrm{a}_{3} \alpha_{3}, \alpha_{3}$ in $\mathrm{G}_{3}{ }^{\prime}$ then $\left|\alpha_{1}\right|=\left|\alpha_{2}\right|=\left|\alpha_{3}\right|$

Example 3.1 Consider a very simple matrix grammar $\mathrm{M}=\left(\mathrm{G}, \mathrm{G}^{\prime}\right)$ where $\mathrm{G}=$ $\left(\{S, B, D\},\left\{S_{1}, S_{2}, S_{3}, S_{4}\right\},\left\{\begin{array}{l}S \rightarrow S_{1} B, B \rightarrow S_{2} B D, \\ D \rightarrow S_{3} B, B \rightarrow S_{4}\end{array}\right\}, S\right)$ 
$\mathrm{G}^{\prime}=\mathrm{G}_{1}{ }^{\prime} \bigcup \mathrm{G}_{2}{ }^{\prime} \bigcup \mathrm{G}_{3}{ }^{\prime} \bigcup \mathrm{G}_{4}{ }^{\prime}$ where

$\mathrm{G}_{\mathrm{i}}{ }^{\prime}=\left(\mathrm{V}_{\mathrm{i}}, \mathrm{T}_{\mathrm{i}}, \mathrm{P}_{\mathrm{i}}, \mathrm{S}_{\mathrm{i}}\right)$ where

$\mathrm{V}_{\mathrm{i}}=\left\{S_{i}, B_{i}, C_{i}, D_{i}, E_{i}, F_{i}, G_{i}\right\}$,

$\left\{a_{i}, b_{i}, c_{i}, d_{i}, e_{i}, f_{i}, g_{i}\right\} \mathrm{P}_{\mathrm{i}}=\left[\begin{array}{l}S_{i} \rightarrow a_{i} B_{i} C_{i} \\ B_{i} \rightarrow b_{i} \\ C_{i} \rightarrow c_{i} D_{i} \\ D_{i} \rightarrow d_{i} \\ E_{i} \rightarrow e_{i} C_{i} \\ C_{i} \rightarrow f_{i} G_{i} \\ G_{i} \rightarrow g_{i}\end{array}\right]$

for $\mathrm{i}=1,2,3,4$

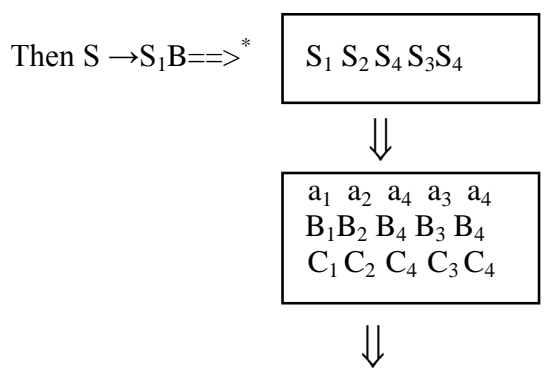

$a_{1} a_{2} a_{4} a_{3} a_{4}$

$b_{1} b_{2} b_{4} b_{3} b_{4}$

... $\cdot \cdot$

. . . .

$\mathrm{G}_{1} \mathrm{G}_{2} \mathrm{G}_{4} \mathrm{G}_{3} \mathrm{G}_{4}$

\section{$\forall$}

$\begin{array}{|lllll|}\mathrm{a}_{1} & \mathrm{a}_{2} & \mathrm{a}_{4} & \mathrm{a}_{3} & \mathrm{a}_{4} \\ \mathrm{~b}_{1} & \mathrm{~b}_{2} & \mathrm{~b}_{4} & \mathrm{~b}_{3} & \mathrm{~b}_{4} \\ \mathrm{c}_{1} & \mathrm{c}_{2} & \mathrm{c}_{4} & \mathrm{c}_{3} & \mathrm{c}_{4} \\ \mathrm{~d}_{1} & \mathrm{~d}_{2} & \mathrm{~d}_{4} & \mathrm{~d}_{3} & \mathrm{~d}_{4} \\ \mathrm{e}_{1} & \mathrm{e}_{2} & \mathrm{e}_{4} & \mathrm{e}_{3} & \mathrm{e}_{4} \\ \mathrm{f}_{1} & \mathrm{f}_{2} & \mathrm{f}_{4} & \mathrm{f}_{3} & \mathrm{f}_{4} \\ \mathrm{~g}_{1} & \mathrm{~g}_{2} & \mathrm{~g}_{4} & \mathrm{~g}_{3} & \mathrm{~g}_{4} \\ & & & & \end{array}$

In the above example the set of all Matrices generated by $\mathrm{M}$ is $\mathrm{L}(\mathrm{M})=\left\{\mathrm{S}_{1}\left[\mathrm{~S}_{2}{ }^{\mathrm{n}}\left(\mathrm{S}_{4} \mathrm{~S}_{3}\right)^{\mathrm{m}}\right]^{\mathrm{k}} \mathrm{S}_{4} / \mathrm{n}, \mathrm{k} \geq 0\right.$ and $\left.0 \leq \mathrm{m} \leq \mathrm{n}+1\right\}$

Definition 3.3 A positive presentation of a language $\mathrm{L}$ is an infinite sequence of strings $\mathrm{M}_{1}, \mathrm{M}_{2}, \ldots$ such that $\left\{\mathrm{M} \mid \mathrm{M}=\mathrm{M}_{\mathrm{i}}\right.$ for some $\left.\mathrm{i}\right\}=\mathrm{L}$

Definition 3.4 A class of languages $L=\left\{L_{1}, L_{2} \ldots\right\}$ is said to be inferable from positive data if there exists an Identification Algorithm IA such that $M$ on input $\sigma$ converges to $L$ with $\mathrm{L}_{\mathrm{j}}=\mathrm{L}_{\mathrm{i}}$ for any index $\mathrm{i}$ and any positive presentation $\sigma$ on $\mathrm{L}_{\mathrm{i}}$

Lemma 3.1 Let $L$ be a very simple matrix language. Then for each matrix $\left[a_{i j}\right]$ in $\mathrm{L} \mathrm{i}=1,2 . . \mathrm{m}, \mathrm{j}=1,2 . . \mathrm{n}, \mathrm{n} \geq 2$ the symbols of first and last columns must be different.

Example 3.2 i) For the rule in $P: S \rightarrow S_{1} A B, A \rightarrow S_{2} S_{2}$, $B \rightarrow S_{1}$, we get $\left\{S_{1} S_{2} S_{2} S_{1}\right\}$ as it is not a very simple matrix language.

ii) $\left\{\mathrm{S}_{1}{ }^{\mathrm{n}}\right\}$ is not a very simple matrix language as $\mathrm{S} \rightarrow \mathrm{S}_{1} \mathrm{~S}$, $\mathrm{S} \rightarrow \mathrm{S}_{1}$ gives no unique $\mathrm{S}_{1}$-handle rule iii) $\left\{\mathrm{S}_{1}{ }^{\mathrm{n}} \mathrm{S}_{2} \mathrm{~S}_{1}{ }^{\mathrm{m}} / \mathrm{m}, \mathrm{n} \geq 0\right\}$ is not a very simple matrix language as $\mathrm{S} \rightarrow \mathrm{S}_{1} \mathrm{SA}, \mathrm{S} \rightarrow \mathrm{S}_{2}, \mathrm{~A} \rightarrow \mathrm{S}_{1} \mathrm{~S}_{1}$ gives no unique $\mathrm{S}_{1}$-handle rule

\section{Closure properties}

Theorem 3.1 The class of very simple matrix languages is closed under none of the following: union, concatenation, intersection, complement, kleene closure $(+, *), \quad(\lambda$-free $)$ homomorphism, inverse homomorphism or reversal.

Proof (Union) Consider the very simple matrix languages

$\mathrm{L}_{1}=\left[\begin{array}{ll}a_{1} & a_{2} \\ b_{1} & b_{2} \\ c_{1} & c_{2} \\ d_{1} & d_{2} \\ e_{1} & e_{2} \\ f_{1} & f_{2} \\ g_{1} & g_{2}\end{array}\right]$ and $\mathrm{L}_{2}=\left[\begin{array}{c}a_{1} \\ b_{1} \\ c_{1} \\ d_{1} \\ e_{1} \\ f_{1} \\ g_{1}\end{array}\right]$ then

$\mathrm{L}_{1} \cup \mathrm{L}_{2}=\left\{\left[\begin{array}{ll}a_{1} & a_{2} \\ b_{1} & b_{2} \\ c_{1} & c_{2} \\ d_{1} & d_{2} \\ e_{1} & e_{2} \\ f_{1} & f_{2} \\ g_{1} & g_{2}\end{array}\right],\left[\begin{array}{c}a_{1} \\ b_{1} \\ c_{1} \\ d_{1} \\ e_{1} \\ f_{1} \\ g_{1}\end{array}\right]\right\}$ is not a very simple matrix

language as $\mathrm{S} \rightarrow \mathrm{S}_{1} \mathrm{~S}_{2}, \mathrm{~S} \rightarrow \mathrm{S}_{1}$ implies $\mathrm{S}_{1}$-handle rule is not unique

Concatenation Consider a very simple matrix language

$\mathrm{L}_{3}=\left[\begin{array}{ll}a_{2} & a_{1} \\ b_{2} & b_{1} \\ c_{2} & c_{1} \\ d_{2} & d_{1} \\ e_{2} & e_{1} \\ f_{2} & f_{1} \\ g_{2} & g_{1}\end{array}\right]$ then $\mathrm{L}_{1} \mathrm{~L}_{3}$ is not a very simple matrix

language as the rules which generate $\mathrm{L}_{1} \mathrm{~L}_{3}$

i.e., $\mathrm{S} \rightarrow \mathrm{S}_{1} \mathrm{Y} \mathrm{S}_{2} \mathrm{X}, \mathrm{X} \rightarrow \mathrm{S}_{1}, \mathrm{Y} \rightarrow \mathrm{S}_{2}$ implies that the

$S_{1}$-handle rule is not unique

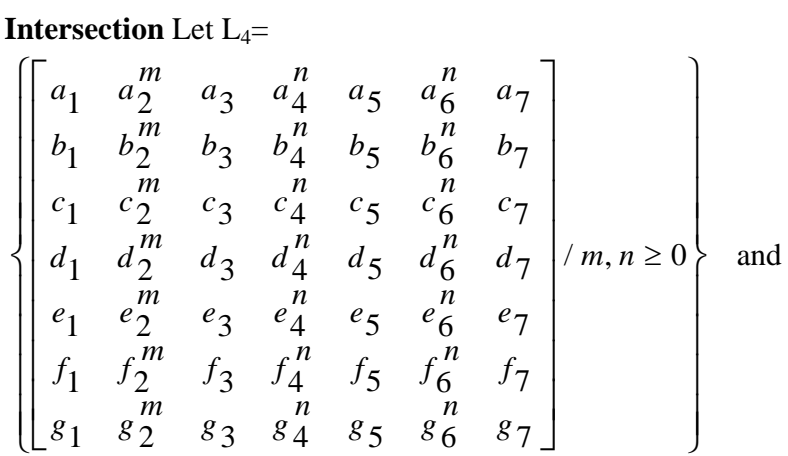


$\mathrm{L}_{5}=\left\{\left[\begin{array}{lllllll}a_{1} & a_{2}^{n} & a_{3} & a_{4}^{m} & a_{5} & a_{6}^{m} & a_{7} \\ b_{1} & b_{2}^{n} & b_{3} & b_{4}^{m} & b_{5} & b_{6}^{m} & b_{7} \\ c_{1} & c_{2}^{n} & c_{3} & c_{4}^{m} & c_{5} & c_{6}^{m} & c_{7} \\ d_{1} & d_{2}^{n} & d_{3} & d_{4}^{m} & d_{5} & d_{6}^{m} & d_{7} \\ e_{1} & e_{2}^{n} & e_{3} & e_{4}^{m} & e_{5} & e_{6}^{m} & e_{7} \\ f_{1} & f_{2}^{n} & f_{3} & f_{4}^{m} & f_{5} & f_{6}^{m} & f_{7} \\ g_{1} & g_{2}^{n} & g_{3} & g_{4}^{m} & g_{5} & g_{6}^{m} & g_{7}\end{array}\right] / m, n \geq 0\right\}$

then

$$
\mathrm{L}_{4} \cap \mathrm{L}_{5}=\left\{\left[\begin{array}{ccccccc}
a_{1} & a_{2}^{m} & a_{3} & a_{4}^{m} & a_{5} & a_{6}^{m} & a_{7} \\
b_{1} & b_{2}^{m} & b_{3} & b_{4}^{m} & b_{5} & b_{6}^{m} & b_{7} \\
c_{1} & c_{2}^{m} & c_{3} & c_{4}^{m} & c_{5} & c_{6}^{m} & c_{7} \\
d_{1} & d_{2}^{m} & d_{3} & d_{4}^{m} & d_{5} & d_{6}^{m} & d_{7} \\
e_{1} & e_{2}^{m} & e_{3} & e_{4}^{m} & e_{5} & e_{6}^{m} & e_{7} \\
f_{1} & f_{2}^{m} & f_{3} & f_{4}^{m} & f_{5} & f_{6}^{m} & f_{7} \\
g_{1} & g_{2}^{m} & g_{3} & g_{4}^{m} & g_{5} & g_{6}^{m} & g_{7}
\end{array}\right] / m \geq 0\right\}
$$

is not-context free.

Complement Let $\mathrm{L}_{6}=\left[\begin{array}{c}a_{2} \\ b_{2} \\ c_{2} \\ d_{2} \\ e_{2} \\ f_{2} \\ g_{2}\end{array}\right]$ a very simple matrix language

over $\Sigma$, while its complement $\mathrm{L}_{6}{ }^{\mathrm{c}}=\Sigma^{*}-\mathrm{L}_{6}$ is not a very simple matrix language as the rules i.e., $\mathrm{S} \rightarrow \mathrm{S}_{1} \mathrm{~S}, \mathrm{~S} \rightarrow \mathrm{S}_{1}$ which generates $\mathrm{L}_{6}{ }^{\mathrm{c}}$ implies $\mathrm{S}_{1}$-handle rule is not unique

Kleene Closure Consider again $\mathrm{L}_{6}$, then $\mathrm{L}_{6}{ }^{*}\left(\right.$ or $\mathrm{L}_{6}{ }^{+}$) is not a very simple matrix language as the rules $\mathrm{S} \rightarrow \mathrm{S}_{1} \mathrm{~S}, \mathrm{~S} \rightarrow \mathrm{S}_{1}$ which generate $\mathrm{L}_{6}^{*}$ implies $\mathrm{S}_{1}$-handle rule is not unique

Homomorphism Consider a very simple matrix language

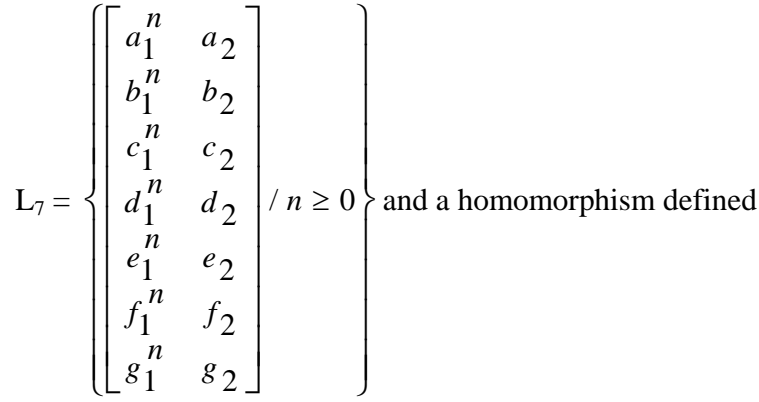

$\mathrm{by} \mathrm{h}_{1}\left(\left[\begin{array}{c}a_{1} \\ b_{1} \\ c_{1} \\ d_{1} \\ e_{1} \\ f_{1} \\ g_{1}\end{array}\right]\right)=\left[\begin{array}{c}a_{1} \\ b_{1} \\ c_{1} \\ d_{1} \\ e_{1} \\ f_{1} \\ g_{1}\end{array}\right]$ and $\mathrm{h}_{1}\left(\left[\begin{array}{c}a_{2} \\ b_{2} \\ c_{2} \\ d_{2} \\ e_{2} \\ f_{2} \\ g_{2}\end{array}\right]\right)=\Lambda$

Then $\mathrm{h}_{1}\left(\mathrm{~L}_{7}\right)=\left\{\left[\begin{array}{c}a_{1}^{n} \\ b_{1}^{n} \\ c_{1}^{n} \\ d_{1}^{n} \\ e_{1}^{n} \\ f_{1}^{n} \\ g_{1}^{n}\end{array}\right] / n \geq 0\right\}$ is not a very simple matrix

language as $\mathrm{S} \rightarrow \mathrm{S}_{1} \mathrm{~S}, \mathrm{~S} \rightarrow \mathrm{S}_{1}$ implies $\mathrm{S}_{1}$-handle rule is not unique

Inverse Homomorphism For a very simple matrix language $\mathrm{L}_{6}=\left[\begin{array}{l}a_{2} \\ b_{2} \\ c_{2} \\ d_{2} \\ e_{2} \\ f_{2} \\ g_{2}\end{array}\right]$, consider a homomorphism h defined by $\mathrm{h}\left(\left[\begin{array}{l}a_{1} \\ b_{1} \\ c_{1} \\ d_{1} \\ e_{1} \\ f_{1} \\ g_{1}\end{array}\right]\right)=\left[\begin{array}{l}a_{2} \\ b_{2} \\ c_{2} \\ d_{2} \\ e_{2} \\ f_{2} \\ g_{2}\end{array}\right]$ and $\mathrm{h}\left(\left[\begin{array}{l}a_{3} \\ b_{3} \\ c_{3} \\ d_{3} \\ e_{3} \\ f_{3} \\ g_{3}\end{array}\right]\right)=\Lambda$.

Then $^{-1}\left(\mathrm{~L}_{6}\right)=\left\{\left[\begin{array}{ccc}a_{3}^{m} & a_{1} & a_{3}^{n} \\ b_{3}^{m} & b_{1} & b_{3}^{n} \\ c_{3}^{m} & c_{1} & c_{3}^{n} \\ d_{3}^{m} & d_{1} & d_{3}^{n} \\ e_{3}^{m} & e_{1} & e_{3}^{n} \\ f_{3}^{m} & f_{1} & f_{3}^{n} \\ g_{3}^{m} & g_{1} & g_{3}^{n}\end{array}\right] / m, n \geq 0\right\}$

is not very simple matrix language as

$\mathrm{S} \rightarrow \mathrm{X}, \mathrm{X} \rightarrow \mathrm{S}_{3} \mathrm{X}, \mathrm{X} \rightarrow \mathrm{S}_{1}, \mathrm{X} \rightarrow \mathrm{S}_{1} \mathrm{Y}, \mathrm{Y} \rightarrow \mathrm{S}_{3}$ implies $\mathrm{S}_{1}$-handle rule is not unique

Reversal Consider a very simple matrix language $\mathrm{L}_{7}$ then its reversal $L_{7}^{R}$ is not a very simple matrix language as the rules $\mathrm{S} \rightarrow \mathrm{S}_{2} \mathrm{X}, \quad \mathrm{X} \rightarrow \mathrm{S}_{1} \mathrm{X}, \quad \mathrm{X} \rightarrow \mathrm{S}_{1}$ which generates $\mathrm{L}_{7}^{\mathrm{R}}$ 
implies that $\mathrm{S}_{1}$-handle rule is not unique

\section{LEARNING VERY SIMPLE MATRIX GRAMMAR AND LANGUAGE}

We extend the algorithm given in [1] and use the schema representation method to learn the class of very simple matrix language. For the purpose of learning, we consider the following string representation of each column of the matrix using a mapping $\chi$.

Definition 4.1 Let $\mathrm{x}$ be a matrix (or an image) defined over $\Sigma$, then $(\mathrm{x})^{\mathrm{i}+1}=(\mathrm{x})^{\mathrm{i}} \Phi \mathrm{x}$ and $(\mathrm{x})_{\mathrm{i}+1}=(\mathrm{x})_{\mathrm{i}} \Theta \mathrm{x}, \mathrm{i} \geq 1$

A mapping $\chi$ is defined as follows:

$\chi: \Sigma^{+} \rightarrow \Sigma_{+}$such that for any string $\mathrm{s}=\mathrm{a}_{1} \mathrm{a}_{2} \ldots \mathrm{a}_{\mathrm{n}} \in \Sigma^{+}$

Let $\mathrm{I}=\mathrm{c}_{1} \Theta \mathrm{c}_{2} \Theta \ldots . \Theta \mathrm{c}_{\mathrm{n}}$ be the image defined over $\Sigma_{+} \mathrm{I} \in$ $L(M)$ if and only if there exists $S_{1} S_{2} \ldots S_{n} \in L(G)$ such that $c_{j}$ $\in \mathrm{L}\left(\mathrm{G}_{\mathrm{i}}{ }^{\prime}\right), \quad 1 \leq \mathrm{i} \leq \mathrm{n}$. The string $\mathrm{S}_{1} \mathrm{~S}_{2} \ldots \mathrm{S}_{\mathrm{n}}$ is said to be an intermediate string deriving I with respect to $M$. Note that there can be more than one intermediate string deriving I.

In this section, we consider the following problem for very simple matrix grammars. Suppose that we are given a finite set of $\mathrm{M}$ arrays $\left[\mathrm{a}_{\mathrm{ij}}\right] \mathrm{i}=1 \ldots \mathrm{m}, \mathrm{j}=1 \ldots \mathrm{n}$ from an unknown very simple matrix language $\mathrm{L}(\mathrm{M})$ for some very simple matrix grammar $M=\left(G, G^{\prime}\right)$, the algorithm identifies a ground interpretation $I$ such that $\mathrm{I}(\mathrm{G})$ is consistent with $\mathrm{M}$.

\section{Identification algorithm for very simple matrix grammars Algorithm VSMG}

Input: A positive presentation of very simple matrix language $\mathrm{L}(\mathrm{M})=\mathrm{G} \cup \mathrm{G}^{\prime}$

Output: A sequence of a set of context -free grammars for the horizontal grammar $\mathrm{G}$ over intermediate symbols and the grammar $\mathrm{G}^{\prime}$ for the vertical columns.

\section{Procedure}

Initialize grammar $\mathrm{G}=\left(\left\{\mathrm{p}_{0}\right\}, \Phi, \Phi, \mathrm{p}_{0}, \Phi\right)$

Initialize the set $\mathrm{H}=\Phi$

Initialize the sets $\mathrm{T}_{1}, \mathrm{~T}_{2}, \ldots \mathrm{T}_{\mathrm{k}}=\Phi$

/* Each positive presentation

$\mathrm{M}_{\mathrm{i}} \in \mathrm{M}=\mathrm{c}_{1} \Theta \mathrm{c}_{2} \Theta \ldots . \Theta \mathrm{c}_{\mathrm{n}}(1 \leq \mathrm{n} \leq \mathrm{k})$

$$
=\chi\left(c_{1}\right) \Phi \chi\left(c_{2}\right) \Phi \chi\left(c_{3}\right) \ldots . \Phi \chi\left(c_{n}\right)
$$

Where $\mathrm{c}_{1}, \mathrm{c}_{2}, \ldots \mathrm{c}_{\mathrm{n}} \in \Sigma^{+} *$ /

Step 1 For the first matrix of the sample i.e., $M_{1}$ do

1a. Assign a non terminal $S_{j}(1 \leq j \leq k)$ to each different $\chi\left(c_{n}\right)$ $(1 \leq \mathrm{n} \leq \mathrm{k})$ and store the string of the sequence of $\mathrm{S}_{\mathrm{j}}$ 's corresponding to the sequence $\chi\left(\mathrm{c}_{1}\right) \chi\left(\mathrm{c}_{2}\right) \chi\left(\mathrm{c}_{3}\right) \ldots \chi\left(\mathrm{c}_{\mathrm{n}}\right)$ in a set $\mathrm{H}$.

1b. If $S_{j}(1 \leq j \leq k)$ is the non terminal associated to a column $\chi\left(c_{n}\right)(1 \leq n \leq k)$, put the string $c_{n}(1 \leq n \leq k)$ in the set $T_{j}(1 \leq j \leq k)$

Step 2 For the other matrices of the sample i.e.,

$\mathrm{Mi}=\mathrm{c}_{1} \Theta \mathrm{c}_{2} \Theta \ldots . \Theta \mathrm{c}_{\mathrm{n}}(1 \leq \mathrm{n} \leq \mathrm{k})$

$\mathrm{i} \geq 2$, do

If the string $\mathrm{c}_{1}$ corresponding to $\chi\left(\mathrm{c}_{1}\right)$ has a common prefix and a common suffix with a string $c_{n}(1 \leq n \leq k)$ in some

$\mathrm{Tj}(1 \leq \mathrm{j} \leq \mathrm{k})$, include the string $\mathrm{c}_{1}$ in $\mathrm{T}_{\mathrm{j}}$ ie $\mathrm{T}_{\mathrm{j}}=\mathrm{T}_{\mathrm{j}} \mathrm{U}\left\{\mathrm{c}_{1}\right\}$ and non terminal $S_{j}(1 \leq j \leq k)$ to $\chi\left(c_{1}\right)$. Repeat the same for $c_{2}, c_{3}, \ldots, c_{n}$ and include the string of the sequence of $\mathrm{Sj}$ 's corresponding to $\chi\left(c_{1}\right) \chi\left(c_{2}\right) \chi\left(c_{3}\right) \ldots . \chi\left(c_{n}\right)$ in the set $\mathrm{H}$.
Step 3 Using the identification algorithm IA given below obtain the grammar $\mathrm{G}$ for the input set $\mathrm{H}$, which accepts the context - free matrix grammar $\mathrm{G}$

Step 4 Using the same identification algorithm IA repeatedly we obtain the grammar $\mathrm{G}_{1}{ }^{\prime}, \mathrm{G}_{2}{ }^{\prime} \ldots \mathrm{G}_{\mathrm{k}}{ }^{\prime}$ corresponding to $\mathrm{T}_{1}, \mathrm{~T}_{2}, \ldots, \mathrm{T}_{\mathrm{k}}$.

Lemma 4.1 For a finite subset $R$ of $L\left(G^{*}\right)$, let $I=(f n, f p)=$ Consistent $(R)$ and $G=I\left(G_{0}\right)$. Then either $\mathrm{L}\left(\mathrm{G}^{*}\right)=\mathrm{L}(\mathrm{G})$ or $\mathrm{L}\left(\mathrm{G}^{*}\right)-\mathrm{L}(\mathrm{G}) \neq \phi$

Lemma 4.2 Let $\mathrm{G}_{\mathrm{RO}}, \mathrm{G}_{\mathrm{R} 1} \ldots, \mathrm{G}_{\mathrm{RI}}, \ldots$ be the intermediate (horizontal) sequence of conjectured grammars produced by IA, where $G_{R I}=I_{1}\left(G_{0}\right)$. Then there exists $r \geq 0$ such that for all $\mathrm{i} \geq 0$, produced by $I A$, where $\mathrm{G}_{\mathrm{Rr}}=\mathrm{Ii}\left(\mathrm{G}_{0, \Sigma}\right)$. Then there exists $r \geq 0$ such that for all $\mathrm{i} \geq 0, \mathrm{G}_{\mathrm{Rr}}=\mathrm{G}_{\mathrm{Rr}+1}$ and $\mathrm{L}\left(\mathrm{G}_{\mathrm{Rr}}\right)=\mathrm{L}\left(\mathrm{G}_{*}\right)$ and similarly let $\mathrm{G}_{\mathrm{R} 0}{ }^{\prime}, \mathrm{G}_{\mathrm{R} 1}{ }^{\prime}, \ldots \mathrm{G}_{\mathrm{Ri}}{ }^{\prime} \ldots$ be the vertical sequence of conjectured grammars produced by IA, where $\mathrm{G}_{\mathrm{Rr}}{ }^{\prime}=\mathrm{I}_{\mathrm{i}}\left(\mathrm{G}_{0, \Sigma}\right)$. Then there exists $r \geq 0$ su ch that for all $\mathrm{I} \geq 0, \mathrm{G}_{\mathrm{Rr}}{ }^{\prime}=\mathrm{G}_{\mathrm{Rr}+1}{ }^{\prime}$ and $\mathrm{L}\left(\mathrm{G}_{\mathrm{Rr}}{ }^{\prime}\right)=\mathrm{L}\left(\mathrm{G}_{*}\right)$ where $\mathrm{G}_{0, \Sigma}=\left(\{\mathrm{S}\} \cup \mathrm{V}_{\mathrm{N}, \Sigma}, \Sigma, \mathrm{P}_{\Sigma}, \mathrm{S}\right)$ where $\mathrm{V}_{\mathrm{N}, \Sigma}=\left\{\mathrm{X}_{\mathrm{a}} / \mathrm{a} \in \Sigma\right\}$ and $\mathrm{P}_{\Sigma}=\left\{\mathrm{X}_{\mathrm{a}} \rightarrow \mathrm{ax}_{\mathrm{a}} / \mathrm{a} \in \Sigma\right\}$

Proof From the property of IA, in particular, of the procedure consistent $(\mathrm{R})$, there is an upper bound $\mathrm{B}$ (depending on the size of $G^{*}$ ) for which each $i \geq 1$, the number of candidate interpretations Ii (=consistent $(\mathrm{Ri})$ ) for the $\mathrm{i}$-th conjecture $\mathrm{G}_{\mathrm{Ri}}$ is no more than $\mathrm{B}$. (Note that for each $i \geq 1$, and interpretation $I^{*}$ for $G^{*}$ is potentially included in the set of those candidate interpretations Ii). Thus there exists $r \geq 0$ such that for all $i \geq 0, G_{R r}=G_{R r+1}$. Suppose that $\mathrm{L}\left(\mathrm{G}^{*}\right) \neq \mathrm{L}\left(\mathrm{G}_{\mathrm{Rr}}\right)$, then by the preceding lemma there exists a string $\mathrm{w} \in \mathrm{L}\left(\mathrm{G}^{*}\right)-\mathrm{L}\left(\mathrm{G}_{\mathrm{Rr}}\right)$ such that $\mathrm{w}$ is not yet provided as a positive example. This implies that IA produces a conjecture distinct from $\mathrm{G}_{\mathrm{Rr}}$, a contradiction

Thus we have the following

Theorem 4.1 The class of very simple grammars is identifiable in the limit from positive data.

\section{Identification Algorithm IA}

Input: A positive presentation of a very simple matrix language $\mathrm{L}\left(\mathrm{G}_{*}\right)$

Output: A sequence of very simple grammars $G_{R 0}, G_{R 1} \ldots \ldots$ Procedure

Initialize $\mathrm{R}_{0}=\varnothing \dot{\varnothing}$

Initialize the grammar schema $\mathrm{G}_{0, \varnothing}$;

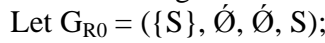

Let $\mathrm{i}=1$;

Repeat (forever)

Read the next positive example $\mathrm{w}_{\mathrm{i}}$;

Let $\mathrm{R}_{\mathrm{i}}=\mathrm{R}_{\mathrm{i}-1} \bigcup\left\{\mathrm{w}_{\mathrm{i}}\right\}$

Let $\operatorname{alph}\left(\mathrm{R}_{1}\right)=\operatorname{alph}\left(\mathrm{R}_{\mathrm{i}-1}\right) \bigcup\left\{\operatorname{alph}\left(\mathrm{w}_{\mathrm{i}}\right)\right\}$;

If $w_{i} \in L\left(G_{R i-1}\right)$, then let $G_{R i}=G_{R i-1}$; Output $\mathrm{G}_{\mathrm{Ri}}$;

Else

$$
\begin{aligned}
& \text { Augment } \mathrm{G}_{0, \Sigma} \text { using } \Sigma=\operatorname{alph}\left(\mathrm{R}_{\mathrm{i}}\right) \text {; } \\
& \text { Let } \mathrm{I}_{\mathrm{i}}=\text { Consistent }(\mathrm{Ri}) \\
& \text { Output } \mathrm{G}_{\mathrm{Ri}}=\mathrm{I}_{\mathrm{i}}\left(\mathrm{G}_{0, \Sigma}\right)
\end{aligned}
$$

Lemma 4.3 Given any very simple matrix grammar $G_{*}$, the algorithm IA identifies in the limit a very simple matrix grammar $G_{R}$ such that $L\left(G_{*}\right)=L\left(G_{R}\right)$, where $R$ is the set of positive data provided

Thus we have the following

Theorem 4.2 The class of very simple matrix grammar is 
identifiable in the limit from positive data.

\section{Constructing a characteristic sample}

Let $L$ be a very simple matrix language. A finite subset $S_{M}$ of $\mathrm{L}$ is called a characteristic sample of $\mathrm{L}$ if and only if $\mathrm{L}$ is the smallest very simple matrix language containing $\mathrm{S}_{\mathrm{M}}$ such that no rule can be applied more than twice.

\section{Time complexity analysis}

\section{Time for updating a conjecture:}

Let $\mathrm{N}=\Sigma_{\mathrm{W}} \in{ }_{\mathrm{R}}$ len $\left(\mathrm{W}_{\mathrm{j}}\right)$ and 1 be the maximum length of positive data in $R$. The time for updating a conjecture is obviously dominated by the time for the procedure consistent $(\mathrm{R})$ where $\mathrm{I}=\left(\mathrm{f}_{\mathrm{n}}, \mathrm{f}_{\mathrm{p}}\right)=$ consistent $(\mathrm{R})$.

In performing consistent $(R)$ determining $f_{n}$ requires atmost $\mathrm{O}(\mathrm{N})$ times. It takes atmost $\mathrm{O}(\mathrm{N})$ times to construct $\operatorname{Lg}(\mathrm{R})$. Solving $\operatorname{Lg}(\mathrm{R})$ requires atmost $\mathrm{O}\left(|\Sigma|^{3}\right)$ time, because it is reduced to the computation of an inverse matrix with atmost $|\Sigma|$ dimension. We have for any

a $\Sigma,-1 \leq \mathrm{n}_{\mathrm{a}} \leq \mathrm{B}(\mathrm{a}, \mathrm{w})$ ( where $\mathrm{B}(\mathrm{a}, \mathrm{w})=\operatorname{len}(\mathrm{w}) / \#_{\mathrm{a}}(\mathrm{w})$ and $\mathrm{w}$ is a string of minimum length in $R_{a}$ ). we see that the value of $n_{a}$ is bounded by 1 , the number of all solution vectors of $\operatorname{Lg}(\mathrm{R})$ is bounded by $1^{|\Sigma|}$. Hence while loops are repeatedly performed atmost $1^{|\Sigma|}$ times. Each while loop requires $\mathrm{O}(\mathrm{N})$ times atmost. Thus the time for updating a conjecture is bounded by $\mathrm{O}\left(|\Sigma|^{3}\right)+\mathrm{O}\left(1^{|\Sigma|}\right) * \mathrm{~N} \leq \mathrm{O}\left(\operatorname{Max}\left\{\mathrm{N}^{|\Sigma|+1} \cdot|\Sigma|^{3}\right\}\right)$

The above is repeated for each column. Therefore repeat $\mathrm{n}$ times if there are $\mathrm{n}$ columns

$\mathrm{O}\left(|\Sigma|^{3}\right)+\mathrm{O}\left(1^{|\Sigma|}\right) * \mathrm{~N} \leq \mathrm{O}\left(\operatorname{Max}\left\{\mathrm{N}^{|\Sigma|+1} \cdot|\Sigma|^{3}\right\}\right)^{\mathrm{n}}$

\section{Example Run}

Consider the very simple matrix grammar given in Example 3.1

Step1 Let $\mathrm{M}_{1}=\left[\begin{array}{lllll}a_{1} & a_{2} & a_{4} & a_{3} & a_{4} \\ b_{1} & b_{2} & b_{4} & b_{3} & b_{4} \\ c_{1} & c_{2} & c_{4} & c_{3} & c_{4} \\ d_{1} & d_{2} & d_{4} & d_{3} & d_{4} \\ e_{1} & e_{2} & e_{4} & e_{3} & e_{4} \\ f_{1} & f_{2} & f_{4} & f_{3} & f_{4} \\ g_{1} & g_{2} & g_{4} & g_{3} & g_{4}\end{array}\right]$

a. $\quad \chi\left(c_{1}\right)=a_{1} b_{1} c_{1} d_{1} e_{1} f_{1} g_{1}-S_{1}$

$\chi\left(c_{2}\right)=a_{2} b_{2} c_{2} d_{2} e_{2} f_{2} g_{2}-S_{2}$

$\chi\left(c_{3}\right)=a_{3} b_{3} c_{3} d_{3} e_{3} f_{3} g_{3}-S_{3}$

$\chi\left(c_{4}\right)=a_{4} b_{4} c_{4} d_{4} e_{4} f_{4} g_{4}-S_{4}$

$\mathrm{H}=\left\{\mathrm{S}_{1} \mathrm{~S}_{2} \mathrm{~S}_{4} \mathrm{~S}_{3} \mathrm{~S}_{4}\right\}$

b. $\mathrm{T}_{1}=\left\{\mathrm{a}_{1} \mathrm{~b}_{1} \mathrm{c}_{1} \mathrm{~d}_{1} \mathrm{e}_{1} \mathrm{f}_{1} \mathrm{~g}_{1}\right\}$

$T_{2}=\left\{a_{2} b_{2} c_{2} d_{2} e_{2} f_{2} g_{2}\right\}$

$T_{3}=\left\{a_{3} b_{3} c_{3} d_{3} e_{3} f_{3} g_{3}\right\}$

$\mathrm{T}_{4}=\left\{\mathrm{a}_{4} \mathrm{~b}_{4} \mathrm{c}_{4} \mathrm{~d}_{4} \mathrm{e}_{4} \mathrm{f}_{4} \mathrm{~g}_{4}\right\}$

Step $2 \mathbf{M}_{2}=\left[\begin{array}{ll}a_{1} & a_{4} \\ b_{1} & b_{4} \\ f_{1} & f_{4} \\ g_{1} & g_{4}\end{array}\right]$

Now $\mathrm{H}=\left\{\mathrm{S}_{1} \mathrm{~S}_{2} \mathrm{~S}_{4} \mathrm{~S}_{3} \mathrm{~S}_{4}, \mathrm{~S}_{1} \mathrm{~S}_{4}\right\}$

$\mathrm{T}_{1}=\left\{\mathrm{a}_{1} \mathrm{~b}_{1} \mathrm{c}_{1} \mathrm{~d}_{1} \mathrm{e}_{1} \mathrm{f}_{1} \mathrm{~g}_{1}, \mathrm{a}_{1} \mathrm{~b}_{1} \mathrm{f}_{1} \mathrm{~g}_{1}\right\}$

$T_{2}=\left\{a_{2} b_{2} c_{2} d_{2} e_{2} f_{2} g_{2}, a_{2} b_{2} f_{2} g_{2}\right\}$

$T_{3}=\left\{a_{3} b_{3} c_{3} d_{3} e_{3} f_{3} g_{3}, a_{3} b_{3} f_{3} g_{3}\right\}$

$\mathrm{T}_{4}=\left\{\mathrm{a}_{4} \mathrm{~b}_{4} \mathrm{c}_{4} \mathrm{~d}_{4} \mathrm{e}_{4} \mathrm{f}_{4} \mathrm{~g}_{4}, \mathrm{a}_{4} \mathrm{~b}_{4} \mathrm{f}_{4} \mathrm{~g}_{4}\right\}$
$\mathbf{M}_{3}=\left[\begin{array}{llllll}a_{1} & a_{2} & a_{2} & a_{4} & a_{3} & a_{4} \\ b_{1} & b_{2} & b_{2} & b_{4} & b_{3} & b_{4} \\ c_{1} & c_{2} & c_{2} & c_{4} & c_{3} & c_{4} \\ d_{1} & d_{2} & d_{2} & d_{4} & d_{3} & d_{4} \\ e_{1} & e_{2} & e_{2} & e_{4} & e_{3} & e_{4} \\ f_{1} & f_{2} & f_{2} & f_{4} & f_{3} & f_{4} \\ g_{1} & g_{2} & g_{2} & g_{4} & g_{3} & g_{4}\end{array}\right]$

$\mathrm{H}=\left\{\mathrm{S}_{1} \mathrm{~S}_{2} \mathrm{~S}_{4} \mathrm{~S}_{3} \mathrm{~S}_{4}, \mathrm{~S}_{1} \mathrm{~S}_{4}, \mathrm{~S}_{1} \mathrm{~S}_{2} \mathrm{~S}_{2} \mathrm{~S}_{4} \mathrm{~S}_{3} \mathrm{~S}_{4}\right\}$

$\mathrm{T}_{1}=\left\{\mathrm{a}_{1} \mathrm{~b}_{1} \mathrm{c}_{1} \mathrm{~d}_{1} \mathrm{e}_{1} \mathrm{f}_{1} \mathrm{~g}_{1}, \mathrm{a}_{1} \mathrm{~b}_{1} \mathrm{f}_{1} \mathrm{~g}_{1}\right\}$

$\mathrm{T}_{2}=\left\{\mathrm{a}_{2} \mathrm{~b}_{2} \mathrm{c}_{2} \mathrm{~d}_{2} \mathrm{e}_{2} \mathrm{f}_{2} \mathrm{~g}_{2}, \mathrm{a}_{2} \mathrm{~b}_{2} \mathrm{f}_{2} \mathrm{~g}_{2}\right\}$

$T_{3}=\left\{a_{3} b_{3} c_{3} d_{3} e_{3} f_{3} g_{3}, a_{3} b_{3} f_{3} g_{3}\right\}$

$\mathrm{T}_{4}=\left\{\mathrm{a}_{4} \mathrm{~b}_{4} \mathrm{c}_{4} \mathrm{~d}_{4} \mathrm{e}_{4} \mathrm{f}_{4} \mathrm{~g}_{4}, \mathrm{a}_{4} \mathrm{~b}_{4} \mathrm{f}_{4} \mathrm{~g}_{4}\right\}$

$\mathbf{M}_{4}=\left[\begin{array}{lllll}a_{1} & a_{2} & a_{4} & a_{3} & a_{4} \\ b_{1} & b_{2} & b_{4} & b_{3} & b_{4} \\ c_{1} & c_{2} & c_{4} & c_{3} & c_{4} \\ d_{1} & d_{2} & d_{4} & d_{3} & d_{4} \\ e_{1} & e_{2} & e_{4} & e_{3} & e_{4} \\ c_{1} & c_{2} & c_{4} & c_{3} & c_{4} \\ d_{1} & d_{2} & d_{4} & d_{3} & d_{4} \\ e_{1} & e_{2} & e_{4} & e_{3} & e_{4} \\ f_{1} & f_{2} & f_{4} & f_{3} & f_{4} \\ g_{1} & g_{2} & g_{4} & g_{3} & g_{4}\end{array}\right]$

Again $\mathrm{H}=\left\{\mathrm{S}_{1} \mathrm{~S}_{2} \mathrm{~S}_{4} \mathrm{~S}_{3} \mathrm{~S}_{4}, \mathrm{~S}_{1} \mathrm{~S}_{4}, \mathrm{~S}_{1} \mathrm{~S}_{2} \mathrm{~S}_{2} \mathrm{~S}_{4} \mathrm{~S}_{3} \mathrm{~S}_{4}\right\}$

$T_{1}=\left\{a_{1} b_{1} c_{1} d_{1} e_{1} f_{1} g_{1}, a_{1} b_{1} f_{1} g_{1}, a_{1} b_{1} c_{1} d_{1} e_{1} c_{1} d_{1} e_{1} f_{1} g_{1}\right\}$ $T_{2}=\left\{a_{2} b_{2} c_{2} d_{2} e_{2} f_{2} g_{2}, a_{2} b_{2} f_{2} g_{2}, a_{2} b_{2} c_{2} d_{2} e_{2} c_{2} d_{2} e_{2} f_{2} g_{2}\right\}$ $T_{3}=\left\{a_{3} b_{3} c_{3} d_{3} e_{3} f_{3} g_{3}, a_{3} b_{3} f_{3} g_{3}, a_{3} b_{3} c_{3} d_{3} e_{3} c_{3} d_{3} e_{3} f_{3} g_{3}\right\}$ $\mathrm{T}_{4}=\left\{\mathrm{a}_{4} \mathrm{~b}_{4} \mathrm{c}_{4} \mathrm{~d}_{4} \mathrm{e}_{4} \mathrm{f}_{4} \mathrm{~g}_{4}, \mathrm{a}_{4} \mathrm{~b}_{4} \mathrm{f}_{4} \mathrm{~g}_{4}, \mathrm{a}_{4} \mathrm{~b}_{4} \mathrm{c}_{4} \mathrm{~d}_{4} \mathrm{e}_{4} \mathrm{c}_{4} \mathrm{~d}_{4} \mathrm{e}_{4} \mathrm{f}_{4} \mathrm{~g}_{4}\right\}$

$\mathbf{M}_{5}=\left[\begin{array}{llllllll}a_{1} & a_{2} & a_{2} & a_{4} & a_{3} & a_{4} & a_{3} & a_{4} \\ b_{1} & b_{2} & b_{2} & b_{4} & b_{3} & b_{4} & b_{3} & b_{4} \\ c_{1} & c_{2} & c_{2} & c_{4} & c_{3} & c_{4} & c_{3} & c_{4} \\ d_{1} & d_{2} & d_{2} & d_{4} & d_{3} & d_{4} & d_{3} & d_{4} \\ e_{1} & e_{2} & e_{2} & e_{4} & e_{3} & e_{4} & e_{3} & e_{4} \\ f_{1} & f_{2} & f_{2} & f_{4} & f_{3} & f_{4} & f_{3} & f_{4} \\ g_{1} & g_{2} & g_{2} & g_{4} & g_{3} & g_{4} & g_{3} & g_{4}\end{array}\right]$

Again

$\mathrm{H}=\left\{\mathrm{S}_{1} \mathrm{~S}_{2} \mathrm{~S}_{4} \mathrm{~S}_{3} \mathrm{~S}_{4}, \mathrm{~S}_{1} \mathrm{~S}_{4}, \mathrm{~S}_{1} \mathrm{~S}_{2} \mathrm{~S}_{2} \mathrm{~S}_{4} \mathrm{~S}_{3} \mathrm{~S}_{4}, \mathrm{~S}_{1} \mathrm{~S}_{2} \mathrm{~S}_{2} \mathrm{~S}_{4} \mathrm{~S}_{3} \mathrm{~S}_{4} \mathrm{~S}_{3} \mathrm{~S}_{4}\right\}$

$\mathrm{T}_{1}=\left\{\mathrm{a}_{1} \mathrm{~b}_{1} \mathrm{c}_{1} \mathrm{~d}_{1} \mathrm{e}_{1} \mathrm{f}_{1} \mathrm{~g}_{1}, \mathrm{a}_{1} \mathrm{~b}_{1} \mathrm{f}_{1} \mathrm{~g}_{1}, \mathrm{a}_{1} \mathrm{~b}_{1} \mathrm{c}_{1} \mathrm{~d}_{1} \mathrm{e}_{1} \mathrm{c}_{1} \mathrm{~d}_{1} \mathrm{e}_{1} \mathrm{f}_{1} \mathrm{~g}_{1}\right\}$

$T_{2}=\left\{a_{2} b_{2} c_{2} d_{2} e_{2} f_{2} g_{2}, a_{2} b_{2} f_{2} g_{2}, a_{2} b_{2} c_{2} d_{2} e_{2} c_{2} d_{2} e_{2} f_{2} g_{2}\right\}$

$T_{3}=\left\{a_{3} b_{3} c_{3} d_{3} e_{3} f_{3} g_{3}, a_{3} b_{3} f_{3} g_{3}, a_{3} b_{3} c_{3} d_{3} e_{3} c_{3} d_{3} e_{3} f_{3} g_{3}\right\}$

$\mathrm{T}_{4}=\left\{\mathrm{a}_{4} \mathrm{~b}_{4} \mathrm{c}_{4} \mathrm{~d}_{4} \mathrm{e}_{4} \mathrm{f}_{4} \mathrm{~g}_{4}, \mathrm{a}_{4} \mathrm{~b}_{4} \mathrm{f}_{4} \mathrm{~g}_{4}, \mathrm{a}_{4} \mathrm{~b}_{4} \mathrm{c}_{4} \mathrm{~d}_{4} \mathrm{e}_{4} \mathrm{c}_{4} \mathrm{~d}_{4} \mathrm{e}_{4} \mathrm{f}_{4} \mathrm{~g}_{4}\right\}$

$\mathrm{M}_{6}=$

$\left[\begin{array}{lllllllllll}a_{1} & a_{2} & a_{2} & a_{4} & a_{3} & a_{4} & a_{3} & a_{2} & a_{4} & a_{3} & a_{4} \\ b_{1} & b_{2} & b_{2} & b_{4} & b_{3} & b_{4} & b_{3} & b_{2} & b_{4} & b_{3} & b_{4} \\ c_{1} & c_{2} & c_{2} & c_{4} & c_{3} & c_{4} & c_{3} & c_{2} & c_{4} & c_{3} & c_{4} \\ d_{1} & d_{2} & d_{2} & d_{4} & d_{3} & d_{4} & d_{3} & d_{2} & d_{4} & d_{3} & d_{4} \\ e_{1} & e_{2} & e_{2} & e_{4} & e_{3} & e_{4} & e_{3} & e_{2} & e_{4} & e_{3} & e_{4} \\ f_{1} & f_{2} & f_{2} & f_{4} & f_{3} & f_{4} & f_{3} & f_{2} & f_{4} & f_{3} & f_{4} \\ g_{1} & g_{2} & g_{2} & g_{4} & g_{3} & g_{4} & g_{3} & g_{2} & g_{4} & g_{3} & g_{4}\end{array}\right]$ Again

$H=\left\{S_{1} S_{2} S_{4} S_{3} S_{4}, S_{1} S_{4}, S_{1} S_{2} S_{2} S_{4} S_{3} S_{4}, S_{1} S_{2} S_{2} S_{4} S_{3} S_{4} S_{3} S_{4}\right.$, $\left.\mathrm{S}_{1} \mathrm{~S}_{2} \mathrm{~S}_{2} \mathrm{~S}_{4} \mathrm{~S}_{3} \mathrm{~S}_{4} \mathrm{~S}_{3} \mathrm{~S}_{2} \mathrm{~S}_{4} \mathrm{~S}_{3} \mathrm{~S}_{4}\right\}$ 
$T_{1}=\left\{a_{1} b_{1} c_{1} d_{1} e_{1} f_{1} g_{1}, a_{1} b_{1} f_{1} g_{1}, a_{1} b_{1} c_{1} d_{1} e_{1} c_{1} d_{1} e_{1} f_{1} g_{1}\right\}$

$T_{2}=\left\{a_{2} b_{2} c_{2} d_{2} e_{2} f_{2} g_{2}, a_{2} b_{2} f_{2} g_{2}, a_{2} b_{2} c_{2} d_{2} e_{2} c_{2} d_{2} e_{2} f_{2} g_{2}\right\}$

$T_{3}=\left\{a_{3} b_{3} c_{3} d_{3} e_{3} f_{3} g_{3}, a_{3} b_{3} f_{3} g_{3}, a_{3} b_{3} c_{3} d_{3} e_{3} c_{3} d_{3} e_{3} f_{3} g_{3}\right\}$

$\mathrm{T}_{4}=\left\{\mathrm{a}_{4} \mathrm{~b}_{4} \mathrm{c}_{4} \mathrm{~d}_{4} \mathrm{e}_{4} \mathrm{f}_{4} \mathrm{~g}_{4}, \mathrm{a}_{4} \mathrm{~b}_{4} \mathrm{f}_{4} \mathrm{~g}_{4}, \mathrm{a}_{4} \mathrm{~b}_{4} \mathrm{c}_{4} \mathrm{~d}_{4} \mathrm{e}_{4} \mathrm{c}_{4} \mathrm{~d}_{4} \mathrm{e}_{4} \mathrm{f}_{4} \mathrm{~g}_{4}\right\}$

\section{Identification of G:}

\section{The computation of $f_{p}$ and $f_{n}$}

1. Let $\mathrm{w}_{1}=\left\{\mathrm{S}_{1} \mathrm{~S}_{4}\right\}$ be the first word from $H$ and $\mathrm{H}_{1}=\left\{\mathrm{w}_{1}\right\}$, alph $\left(H_{1}\right)=\left\{S_{1}, S_{4}\right\}$. Since $S_{4}$ is final $S_{4}$ handle rule is

$X_{S 4} \rightarrow S_{4}$ and $f_{p}\left(X_{S 4}\right)=\lambda\left(n_{S 1} \geq 0\right) f_{n}\left(X_{S 1}\right)=S$ and

$\mathrm{f}_{\mathrm{p}}\left(\mathrm{X}_{\mathrm{S} 1}\right) \neq \lambda$

The length equation for $\mathrm{w}_{1}$ is $\mathrm{n}_{\mathrm{S} 1}+\mathrm{n}_{\mathrm{S} 4}=-1 \ldots \ldots\left(1 . \mathrm{w}_{1}\right)$

$\mathrm{n}_{\mathrm{S} 1}=0 \ldots . .\left(1 . \mathrm{w}_{1}\right)^{\prime}$

$\operatorname{Lg}\left(\mathrm{H}_{1}\right)=\left\{\left(1 . \mathrm{w}_{1}\right)\right\}$

$\operatorname{Lg}\left(\mathrm{H}_{1}{ }^{\prime}\right)=\left\{\left(1 . \mathrm{w}_{1}\right)^{\prime}\right\}$

From the structure graph of $\mathrm{H}$ we get

$\mathrm{f}_{\mathrm{n}}\left(\mathrm{X}_{\mathrm{S} 1}\right)=\mathrm{S}$ and $\mathrm{f}_{\mathrm{n}}(\mathrm{X})=\mathrm{X}$ for every other $\mathrm{X}$

$\chi_{1}=(0)\left(=n_{S 1}\right)$

$\mathrm{CR}\left(\chi_{1}\right)$ is

$\mathrm{S} \rightarrow \mathrm{S}_{1} \mathrm{Z}_{\mathrm{S} 1,1} \quad$ and $\mathrm{X}_{\mathrm{S} 4} \rightarrow \mathrm{S}_{4}$

Simulating the derivation for $\mathrm{w}_{1}$, via these rules we get

$Z_{S 1,1}=X_{S 4}$. As a result we see that CR $\left(\chi_{1}\right)$ is good and a ground interpretation. $I_{1}=\left(f_{n}, f_{p}\right)$ admissible to

$\mathrm{H}_{1}$ is obtained where
$\mathrm{f}_{\mathrm{n}}\left(\mathrm{X}_{\mathrm{S} 1}\right)=\mathrm{S}$
$f_{p}\left(X_{S 1}\right)=X_{S 4}$
$f_{n}(X)=X$ otherwise$$
\mathrm{f}_{\mathrm{p}}\left(\mathrm{X}_{\mathrm{S} 4}\right)=\lambda
$$

The conjectured grammar $\mathrm{G}_{\mathrm{H} 1}=\mathrm{I}_{1}\left(\mathrm{G}_{0, \Sigma}\right)$ is

$\left(\left\{\mathrm{S}, \mathrm{X}_{\mathrm{S} 4}\right\},\left\{\mathrm{X}_{\mathrm{S} 1}, \mathrm{X}_{\mathrm{S}_{4}}\right\}, \mathrm{P}_{1}, \mathrm{~S}\right)$ where $\mathrm{P}_{1}$ is

$\mathrm{S} \rightarrow \mathrm{S}_{1} \mathrm{X}_{\mathrm{S} 4}, \mathrm{X}_{\mathrm{S} 4} \rightarrow \mathrm{S}_{4}$

2. Let $\mathrm{w}_{2}=\left\{\mathrm{S}_{1} \mathrm{~S}_{2} \mathrm{~S}_{4} \mathrm{~S}_{3} \mathrm{~S}_{4}\right\}$ be the second word from $\mathrm{H}$ and $\operatorname{alph}\left(\mathrm{w}_{2}\right)=\left\{\mathrm{S}_{1}, \mathrm{~S}_{2}, \mathrm{~S}_{3}, \mathrm{~S}_{4}\right\}$. Then $\mathrm{H}_{2}=\left\{\mathrm{w}_{1}, \mathrm{w}_{2}\right\}$

Since $S_{4}$ is final $S_{4}$ handle rule is $X_{S_{4}} \rightarrow S_{4}$ and

$\mathrm{f}_{\mathrm{p}}\left(\mathrm{X}_{\mathrm{S} 4}\right)=\lambda\left(\mathrm{n}_{\mathrm{S} 1} \geq 0\right)$

From the structure graph of $\mathrm{H}$ we get

$\mathrm{f}_{\mathrm{n}}\left(\mathrm{X}_{\mathrm{S} 1}\right)=\mathrm{S}$ and

$\mathrm{f}_{\mathrm{n}}(\mathrm{X})=\mathrm{X}$ for every other $\mathrm{X}$

$\mathrm{f}_{\mathrm{p}}\left(\mathrm{X}_{\mathrm{S} 1}\right) \neq \lambda$

and $\operatorname{Lg}\left(\mathrm{H}_{2}\right)=\left\{\left(1 \cdot \mathrm{w}_{1}\right),\left(1 . \mathrm{w}_{2}\right)\right\}$ where

The Length equation for $\mathrm{w}_{2}$ is

$\mathrm{n}_{\mathrm{S} 1}+\mathrm{n}_{\mathrm{S} 2}+\mathrm{n}_{\mathrm{S} 3}+2 \mathrm{n}_{\mathrm{S} 4}=-1 \ldots . .\left(1 . \mathrm{w}_{2}\right)$

$\mathrm{n}_{\mathrm{S} 1}+\mathrm{n}_{\mathrm{S} 2}+\mathrm{n}_{\mathrm{S} 3}=0 \ldots .\left(1 . \mathrm{w}_{2}\right)^{\prime}$

Using the set $\mathrm{H}$, we construct a directed graph called the structure graph of $\mathrm{H}$ as follows

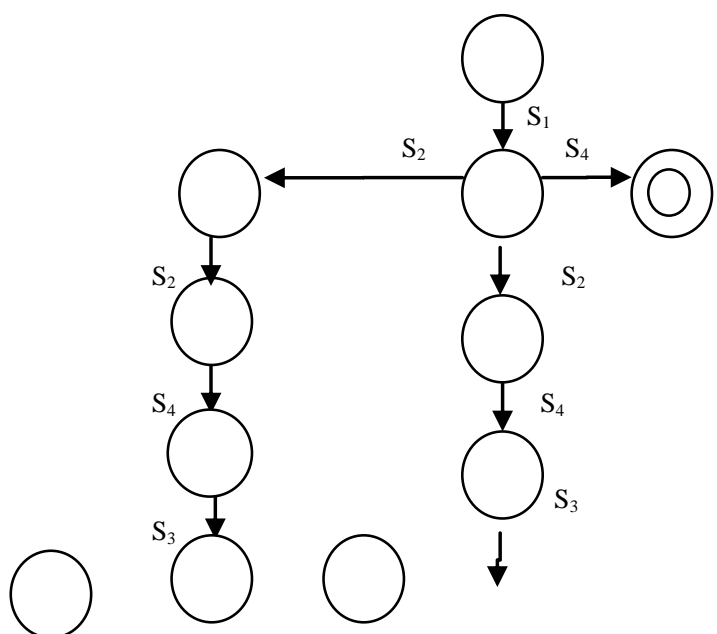

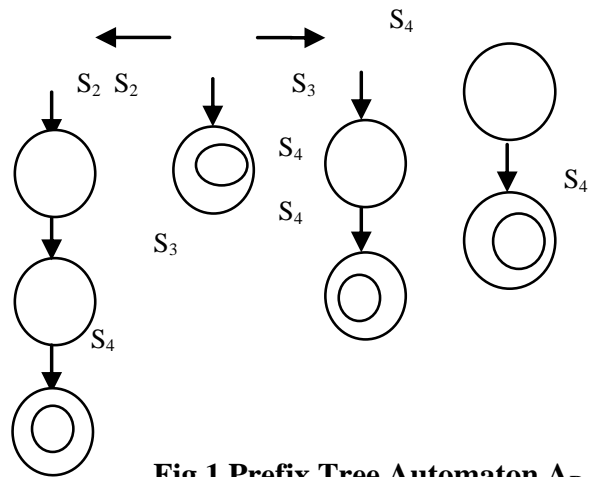

Fig.1 Prefix Tree Automaton $A_{R}$

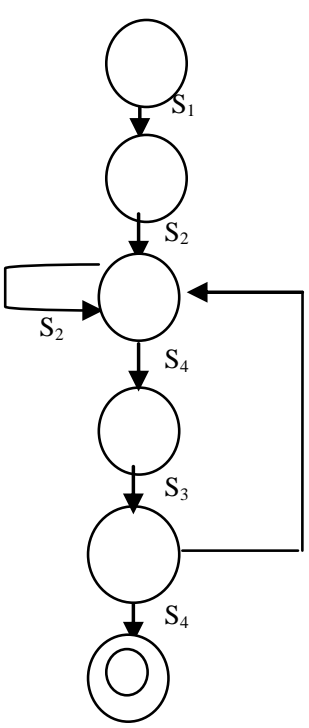

Fig.2 Structured graph $\mathbf{H}$

To solve $\operatorname{Lg}\left(\mathrm{H}_{2}{ }^{\prime}\right)=\left\{\left(1 . \mathrm{w}_{1}\right)^{\prime},\left(1 . \mathrm{w}_{2}\right)^{\prime}\right\}$, we construct an associated matrix $\mathrm{M}_{\mathrm{H} 2}$ and a matrix equation $\mathrm{M}_{\mathrm{H} 2}=\left(\begin{array}{lll|l}1 & 0 & 0 & 0 \\ 1 & 1 & 1 & 0\end{array}\right)$

The matrix computation is done as follows

$\left(\begin{array}{lll|l}1 & 0 & 0 & 0 \\ 1 & 1 & 1 & 0\end{array}\right) \Rightarrow *\left(\begin{array}{lll|l}1 & 0 & 0 & 0 \\ 0 & 1 & 1 & 0\end{array}\right)$

\& solution of $\operatorname{Lg}\left(\mathrm{H}_{2}\right)=\left(\mathrm{n}_{\mathrm{S} 1}=0\right) \cup\left(\mathrm{n}_{\mathrm{S} 2}+\mathrm{n}_{\mathrm{S} 3}=0\right) \Rightarrow \mathrm{n}_{\mathrm{S} 1}=0$ and we may choose a solution vector

$\chi_{2}=(0,2,-1)\left(=\left(\mathrm{n}_{\mathrm{S} 1}, \mathrm{n}_{\mathrm{S} 3}, \mathrm{n}_{\mathrm{S}}\right)\right)$

Hence the set of candidate rules

$\mathrm{CR}\left(\chi_{2}\right)\left\{\mathrm{S} \rightarrow \mathrm{S}_{1} \mathrm{Z}_{\mathrm{S} 1,1}, \mathrm{X}_{\mathrm{S} 2} \rightarrow \mathrm{S}_{2} \mathrm{Z}_{\mathrm{S} 2,1} \mathrm{Z}_{\mathrm{S} 2,2} \mathrm{Z}_{\mathrm{S} 2,3}, \mathrm{X}_{\mathrm{S} 3} \rightarrow \mathrm{S}_{3}\right\}$ is obtained.

Simulating the derivation for $\mathrm{w}_{2}$ via these rules we get $\mathrm{Z}_{\mathrm{S} 1,1}=\mathrm{X}_{\mathrm{S} 2}=\mathrm{X}_{\mathrm{S} 4}, \mathrm{Z}_{\mathrm{S} 2,1}=\mathrm{X}_{\mathrm{S} 4}, \mathrm{ZS}_{2,2}=\mathrm{X}_{\mathrm{S} 3}, \mathrm{Z}_{\mathrm{S} 2,3}=\mathrm{X}_{\mathrm{S} 4}$ $\mathrm{X}_{\mathrm{S} 4} \rightarrow \mathrm{S}_{4}$

We see that CR $\left(\chi_{2}\right)$ is good and a ground interpretation. $I_{2}=\left(f_{n}, f_{p}\right)$ obtained where
$\mathrm{f}_{\mathrm{n}}\left(\mathrm{X}_{\mathrm{S} 1}\right)=\mathrm{S}$
$\mathrm{f}_{\mathrm{p}}\left(\mathrm{X}_{\mathrm{S} 1}\right)=\mathrm{X}_{\mathrm{S} 2} \mathrm{X}_{\mathrm{S} 4}$
$f_{n}\left(X_{S 4}\right)=X_{S 2}$ $f_{p}\left(X_{S 2}\right)=X_{S 3} X_{S 4}$
$f_{n}(X)=X$ otherwise $\mathrm{f}_{\mathrm{p}}\left(\mathrm{X}_{\mathrm{S} 3}\right)=\lambda$

$$
\mathrm{f}_{\mathrm{p}}\left(\mathrm{X}_{\mathrm{S} 4}\right)=\lambda
$$

Thus the conjectured grammar $\mathrm{G}_{\mathrm{H} 2}=\mathrm{I}_{2}\left(\mathrm{G}_{0, \Sigma}\right)$ is $\left(\left\{\mathrm{S}, \mathrm{S}_{2}, \mathrm{~S}_{3}\right\},\left\{\mathrm{S}_{1}, \mathrm{~S}_{2}, \mathrm{~S}_{3}, \mathrm{~S}_{4}\right\}, \mathrm{P}_{2}, \mathrm{~S}\right) \quad$ where $\mathrm{P}_{2}$ is $\mathrm{S} \rightarrow \mathrm{S}_{1} \mathrm{Z}_{\mathrm{S} 1,1} \rightarrow \mathrm{S}_{1} \mathrm{X}_{\mathrm{S} 4} \rightarrow \mathrm{S}_{1} \mathrm{~S}_{4}$ $\mathrm{S} \rightarrow \mathrm{S}_{1} \mathrm{Z}_{\mathrm{S} 1,1} \rightarrow \mathrm{S}_{1} \mathrm{X}_{\mathrm{S} 2} \rightarrow \mathrm{S}_{1} \mathrm{~S}_{2} \mathrm{Z}_{\mathrm{S} 2,1} \mathrm{Z}_{\mathrm{S} 2,2}$ $Z_{\mathrm{S} 2,3} \rightarrow \mathrm{S}_{1} \mathrm{~S}_{2} \mathrm{X}_{\mathrm{S} 4} \mathrm{X}_{\mathrm{S} 3} \mathrm{X}_{\mathrm{S} 4}$ $\mathrm{S} \rightarrow \mathrm{S}_{1} \mathrm{~S}_{2} \mathrm{~S}_{4} \mathrm{~S}_{3} \mathrm{~S}_{4}$ $\mathrm{S} \rightarrow \mathrm{S}_{1} \mathrm{X}_{\mathrm{S} 2} \quad \mathrm{X}_{\mathrm{S} 2} \rightarrow \mathrm{S}_{2} \mathrm{X}_{\mathrm{S} 4} \mathrm{X}_{\mathrm{S} 3} \mathrm{X}_{\mathrm{S} 4}, \quad \mathrm{X}_{\mathrm{S} 3} \rightarrow \mathrm{S}_{3} \quad \mathrm{X}_{\mathrm{S} 4} \rightarrow \mathrm{S}_{4}$ 
3. Let $w_{3}=\left\{S_{1} S_{2} S_{2} S_{4} S_{3} S_{4} S_{3} S_{4}\right\}$ be the third word from $H$ and $\mathrm{H}_{3}=\left\{\mathrm{w}_{1}, \mathrm{w}_{2}, \mathrm{w}_{3}\right\}$ and alph $\left(\mathrm{H}_{3}\right)=\left\{\mathrm{S}_{1}, \mathrm{~S}_{2}, \mathrm{~S}_{3}, \mathrm{~S}_{4}\right\}$.

From the structure graph shown above we have $f_{n}\left(X_{S 1}\right)=S$ and $\mathrm{f}_{\mathrm{p}}\left(\mathrm{X}_{\mathrm{S} 1}\right) \neq \lambda$

Since $S_{4}$ is final, the $S_{4}$ handle rule is $X_{S 4} \rightarrow S_{4}$ and $\mathrm{f}_{\mathrm{p}}\left(\mathrm{X}_{\mathrm{S} 4}\right)=\lambda\left(\mathrm{n}_{\mathrm{S} 1} \geq 0\right)$ and constructs

The IA computes a length equation for $\mathrm{w}_{3}$

$$
\operatorname{Lg}\left(\mathrm{H}_{3}{ }^{\prime}\right)=\left\{\left(1 . \mathrm{w}_{1}\right)^{\prime},\left(1 . \mathrm{w}_{2}\right)^{\prime},\left(1 . \mathrm{w}_{3}\right)^{\prime}\right\} \text { where }
$$

$\mathrm{n}_{\mathrm{S} 1}+2 \mathrm{n}_{\mathrm{S} 2}+2 \mathrm{n}_{\mathrm{S} 3}+3 \mathrm{n}_{\mathrm{S} 4}=-1 \ldots . .\left(1 . \mathrm{w}_{3}\right)$

$\mathrm{n}_{\mathrm{S} 1}+2 \mathrm{n}_{\mathrm{S} 2}+2 \mathrm{n}_{\mathrm{S} 3}=2 \ldots .\left(1 . \mathrm{w}_{3}\right)^{\prime}$

and the associated matrix $\mathrm{M}_{\mathrm{H} 3}$ is

$$
\left(\begin{array}{lll|l}
1 & 0 & 0 & 0 \\
1 & 1 & 1 & 1 \\
1 & 2 & 2 & 2
\end{array}\right) \Rightarrow\left(\begin{array}{lll|l}
1 & 0 & 0 & 0 \\
0 & 0 & 0 & 0 \\
0 & 1 & 1 & 1
\end{array}\right)
$$

Thus the Sol $\left(\operatorname{Lg}\left(\mathrm{H}_{3}{ }^{\prime}\right)\right)=\left(\mathrm{n}_{\mathrm{S} 1}=0\right) \cup\left(\mathrm{n}_{\mathrm{S} 2}+\mathrm{n}_{\mathrm{S} 3}=1\right)$ is obtained from which we may choose a solution vector

$\chi_{3}=(0,2,-1)\left(=\left(\mathrm{n}_{\mathrm{S} 1}, \mathrm{n}_{\mathrm{S} 2}, \mathrm{n}_{\mathrm{S} 3}\right)\right)$

Hence the set of candidate rules $\mathrm{CR}\left(\chi_{3}\right)$ is

$\mathrm{S} \rightarrow \mathrm{S}_{1} \mathrm{Z}_{\mathrm{S} 1,1}, \mathrm{X}_{\mathrm{S} 2} \rightarrow \mathrm{S}_{2} \mathrm{Z}_{\mathrm{S} 2,1} \mathrm{Z}_{\mathrm{S} 2,2} \mathrm{Z}_{\mathrm{S} 2,3}$

$\mathrm{X}_{\mathrm{S} 3} \rightarrow \mathrm{S}_{3} \quad \mathrm{X}_{\mathrm{S} 4} \rightarrow \mathrm{S}_{4}$

Simulating the derivation for $\mathrm{W}_{3}$, via these rules we get $Z_{\mathrm{S} 1,1}=X_{\mathrm{S} 2}=\mathrm{X}_{\mathrm{S} 4}, \mathrm{Z}_{\mathrm{S} 2,1}=\mathrm{X}_{\mathrm{S} 2}=\mathrm{X}_{\mathrm{S} 4}, \mathrm{ZS}_{2,2}=\mathrm{X}_{\mathrm{S} 3}$,

$\mathrm{Z}_{\mathrm{S} 2,3}=\mathrm{X}_{\mathrm{S} 2=} \mathrm{X}_{\mathrm{S} 4}$

We see that $\mathrm{CR}\left(\chi_{3}\right)$ is good and a ground interpretation.

$I_{3}=\left(f_{n}, f_{p}\right)$ is obtained where

$$
\begin{array}{ll}
\mathrm{f}_{\mathrm{n}}\left(\mathrm{X}_{\mathrm{S} 1}\right)=\mathrm{S} & \mathrm{f}_{\mathrm{p}}\left(\mathrm{X}_{\mathrm{S} 1}\right)=\mathrm{X}_{\mathrm{S} 2} \mathrm{X}_{\mathrm{S} 4} \\
\mathrm{f}_{\mathrm{n}}\left(\mathrm{X}_{\mathrm{S} 4}\right)=\mathrm{X}_{\mathrm{S} 2} & \mathrm{f}_{\mathrm{p}}\left(\mathrm{X}_{\mathrm{S} 2}\right)=\mathrm{X}_{\mathrm{S} 2} \mathrm{X}_{\mathrm{S} 3} \mathrm{X}_{\mathrm{S} 4} \\
\mathrm{f}_{\mathrm{n}}(\mathrm{X})=\mathrm{X} \text { otherwise } & \mathrm{f}_{\mathrm{p}}\left(\mathrm{X}_{\mathrm{S} 3}\right)=\lambda
\end{array}
$$

$\mathrm{f}_{\mathrm{p}}\left(\mathrm{X}_{\mathrm{S} 4}\right)=\lambda$

Thus the conjectured grammar $\mathrm{G}_{\mathrm{H} 3}=\mathrm{I}_{3}\left(\mathrm{G}_{0, \Sigma}\right)$ is

$\left(\left\{\mathrm{S}, \mathrm{S}_{2}, \mathrm{~S}_{3}, \mathrm{~S}_{4}\right\},\left\{\mathrm{S}_{1}, \mathrm{~S}_{2}, \mathrm{~S}_{3}, \mathrm{~S}_{4}\right\}, \mathrm{P}_{3}, \mathrm{~S}\right)$ where $\mathrm{P}_{3}$ is

$\mathrm{S} \rightarrow \mathrm{S}_{1} \mathrm{X}_{\mathrm{S} 2} \quad \mathrm{X}_{\mathrm{S} 2} \rightarrow \mathrm{S}_{2} \mathrm{X}_{\mathrm{S} 4} \mathrm{X}_{\mathrm{S} 3} \mathrm{X}_{\mathrm{S} 4}$

$\mathrm{X}_{\mathrm{S} 3} \rightarrow \mathrm{S}_{3} \quad \mathrm{X}_{\mathrm{S} 4} \rightarrow \mathrm{S}_{4}$

4. Let $w_{4}=\left\{S_{1} S_{2} S_{2} S_{4} S_{3} S_{4} S_{3} S_{2} S_{4} S_{3} S_{4}\right\}$ be the fourth word from $\mathrm{H}$ and $\mathrm{H}_{4}=\left\{\mathrm{w}_{1}, \mathrm{w}_{2}, \mathrm{w}_{3}, \mathrm{w}_{4}\right\}$ and

alph $\left(\mathrm{H}_{4}\right)=\left\{\mathrm{S}_{1}, \mathrm{~S}_{2}, \mathrm{~S}_{3}, \mathrm{~S}_{4}\right\}$.

From the structure graph shown above we have $\mathrm{f}_{\mathrm{n}}\left(\mathrm{X}_{\mathrm{S} 1}\right)=\mathrm{S}$ and $\mathrm{f}_{\mathrm{p}}\left(\mathrm{X}_{\mathrm{S} 1}\right) \neq \lambda$

Since $S_{4}$ is final, the $S_{4}$ handle rule is $X_{S 4} \rightarrow S_{4}$ and $\mathrm{f}_{\mathrm{p}}\left(\mathrm{X}_{\mathrm{S} 4}\right)=\lambda\left(\mathrm{n}_{\mathrm{S} 1} \geq 0\right)$

The IA computes a length equation for $\mathrm{w}_{4}$ and constructs $\operatorname{Lg}\left(\mathrm{H}_{4}{ }^{\prime}\right)=\left\{\left(\mathrm{l}_{\mathrm{w}}\right)^{\prime},\left(\mathrm{l} . \mathrm{w}_{2}\right)^{\prime},\left(\mathrm{l} . \mathrm{w}_{3}\right)^{\prime},\left(1 . \mathrm{w}_{4}\right)^{\prime}\right\}$ where $n_{\mathrm{S} 1}+3 n_{\mathrm{S} 2}+3 n_{\mathrm{S} 3}+4 n_{\mathrm{S} 4}=-1 \ldots . .\left(1 . \mathrm{w}_{4}\right)$

$\mathrm{n}_{\mathrm{S} 1}+3 \mathrm{n}_{\mathrm{S} 2}+3 \mathrm{n}_{\mathrm{S} 3=} 3 \ldots .\left(1 . \mathrm{w}_{4}\right)^{\prime}$

and the associated matrix $\mathrm{M}_{\mathrm{H} 4}$ is

$\left(\begin{array}{lll|l}1 & 0 & 0 & 0 \\ 1 & 1 & 1 & 1 \\ 1 & 2 & 2 & 2 \\ 1 & 3 & 3 & 3\end{array}\right) \Rightarrow\left(\begin{array}{lll|l}1 & 0 & 0 & 0 \\ 0 & 1 & 1 & 1 \\ 0 & 0 & 0 & 0 \\ 0 & 0 & 0 & 0\end{array}\right)$
Thus the $\operatorname{Sol}\left(\operatorname{Lg}\left(\mathrm{H}_{4}^{\prime}\right)\right)=\left(\mathrm{n}_{\mathrm{S} 1}=0\right) \cup\left(\mathrm{n}_{\mathrm{S} 2}+\mathrm{n}_{\mathrm{S} 3}=1\right)$ is obtained from which we may choose a solution vector

$\chi_{4}=(0,2,-1)\left(=\left(\mathrm{n}_{\mathrm{S} 1}, \mathrm{n}_{\mathrm{S} 2}, \mathrm{n}_{\mathrm{S} 3}\right)\right)$

The set of candidate rules $\mathrm{CR}\left(\chi_{4}\right)$ is

$\mathrm{S} \rightarrow \mathrm{S}_{1} \mathrm{Z}_{\mathrm{S} 1,1}, \mathrm{X}_{\mathrm{S} 2} \rightarrow \mathrm{S}_{2} \mathrm{Z}_{\mathrm{S} 2,1} \mathrm{Z}_{\mathrm{S} 2,2} \mathrm{Z}_{\mathrm{S} 2,3}$

$\mathrm{X}_{\mathrm{S} 3} \rightarrow \mathrm{S}_{3} \quad \mathrm{X}_{\mathrm{S} 4} \rightarrow \mathrm{S}_{4}$

Simulating the derivation for $\mathrm{W}_{4}$, Via these rules we get

$\mathrm{Z}_{\mathrm{S} 1,1}=\mathrm{X}_{\mathrm{S} 2}=\mathrm{X}_{\mathrm{S} 4}, \mathrm{Z}_{\mathrm{S} 2,1}=\mathrm{X}_{\mathrm{S} 2}=\mathrm{X}_{\mathrm{S} 4}, \mathrm{ZS}_{2,2}=\mathrm{X}_{\mathrm{S} 3}$,

$Z_{\mathrm{S} 2,3}=X_{\mathrm{S} 2=} X_{\mathrm{S} 4}$ We see that $\mathrm{CR}\left(\chi_{4}\right)$ is good and a ground interpretation. $I_{3}=\left(f_{n}, f_{p}\right)$ is obtained where
$\mathrm{f}_{\mathrm{n}}\left(\mathrm{X}_{\mathrm{S} 1}\right)=\mathrm{S}$
$f_{p}\left(X_{S 1}\right)=X_{S 2} X_{S 4}$
$\mathrm{f}_{\mathrm{n}}\left(\mathrm{X}_{\mathrm{S} 4}\right)=\mathrm{X}_{\mathrm{S} 2}$ $\mathrm{f}_{\mathrm{p}}\left(\mathrm{X}_{\mathrm{S} 2}\right)=\mathrm{X}_{\mathrm{S} 2} \mathrm{X}_{\mathrm{S} 3} \mathrm{X}_{\mathrm{S} 4}$
$f_{n}(X)=X$ otherwise $f_{p}\left(X_{S 3}\right)=\lambda$

$$
\mathrm{f}_{\mathrm{p}}\left(\mathrm{X}_{\mathrm{S} 4}\right)=\lambda
$$

Thus the conjectured grammar is

$\mathrm{G}=\mathrm{G}_{\mathrm{H} 4}=\left(\left\{\mathrm{S}, \mathrm{S}_{2}, \mathrm{~S}_{3}, \mathrm{~S}_{4}\right\},\left\{\mathrm{S}_{1}, \mathrm{~S}_{2}, \mathrm{~S}_{3}, \mathrm{~S}_{4}\right\}, \mathrm{P}_{4}, \mathrm{~S}\right)$

where $\mathrm{P}_{4}$ is

$\mathrm{S} \rightarrow \mathrm{S}_{1} \mathrm{X}_{\mathrm{S} 2} \quad \mathrm{X}_{\mathrm{S} 2} \rightarrow \mathrm{S}_{2} \mathrm{X}_{\mathrm{S} 4} \mathrm{X}_{\mathrm{S} 3} \mathrm{X}_{\mathrm{S} 4}$

$\mathrm{X}_{\mathrm{S} 3} \rightarrow \mathrm{S}_{3} \quad \mathrm{X}_{\mathrm{S} 4} \rightarrow \mathrm{S}_{4}$

The conjectured $\mathrm{G}_{\mathrm{H} 4}$ is equivalent to $\mathrm{G}_{*}$. Hence $\mathrm{G}_{\mathrm{H} 4}$ is always an output as a conjecture for all input data afterwards.

\section{Identification of $\mathbf{G}_{\mathbf{i}}$ ' using $\mathbf{T}_{\mathbf{i}}$ :}

The above procedure can be adapted to the sets $T_{1}, T_{2}, T_{3}$ and $T_{4}$ to conjecture the grammars $\mathrm{G}_{1}^{\prime}, \mathrm{G}_{2}^{\prime}, \mathrm{G}_{3}{ }^{\prime}$ and $\mathrm{G}_{4}{ }^{\prime}$ of $\mathrm{G}^{\prime}$

\section{CONCLUSION}

In this paper we have extended the notion of learning very simple grammars of Yokomori[1] to matrix grammars and adopted a modification of the algorithm to learn very simple matrix grammars which in turn can be used to study digitized pictures. The very simple matrix grammar considered here is (CF:CF) matrix grammar. Hence for further study, applications of these grammars to other domains can be considered.

\section{REFERENCES}

[1] Rani Siromoney: On equal matrix languages. Information and control. 14(2)(1969) 135-151

[2] Yokomori T. On polynomial - time identification of very simple grammars from positive data. Theoretical computer science 298 (2003)179-206

[3] A.Rosenfeld and J.L.Pfaltyz. Sequential operations in digital picture processing. J.Assoc.Comput.Mach.13, 1966, pp. 471-494.

[4] Gift Siromoney et al. Abstract families of matrices and picture languages. Computer graphics and image processing (1972) I, (284-307)

[5] Yokomori, T., On polynomial-time learnability in the limit of strictly deterministic automata. Machine learning 19(1995), 153-179. 